\title{
Association of gene polymorphisms with blood pressure and the prevalence of hypertension in community-dwelling Japanese individuals
}

\author{
YOSHIJI YAMADA ${ }^{1}$, FUJIKO ANDO ${ }^{2}$ and HIROSHI SHIMOKATA ${ }^{2}$ \\ ${ }^{1}$ Department of Human Functional Genomics, Life Science Research Center, Mie University, Tsu, Mie; \\ ${ }^{2}$ Department of Epidemiology, National Institute for Longevity Sciences, Obu, Aichi, Japan
}

Received November 23, 2006; Accepted December 29, 2006

\begin{abstract}
Hypertension is a complex multifactorial disorder that is thought to result from an interaction between genetic background and environmental factors. Although various loci and genes have been implicated in predisposition to hypertension by genetic linkage analyses and candidate gene association studies, the genes that confer susceptibility to this condition remain to be identified definitively. We examined the relations of nine candidate gene polymorphisms to blood pressure (BP) and the prevalence of hypertension in a population-based study. The 2238 subjects (1110 women, 1128 men) were aged 40 to 79 years and were randomly recruited for a population-based prospective cohort study of aging and age-related diseases in Japan. BP was measured with subjects having rested in a sitting position for at least $15 \mathrm{~min}$. Genotypes for the 160C $\rightarrow \mathrm{T}$ (Arg54Trp) polymorphism of $Q P C T$, the $\mathrm{C} \rightarrow \mathrm{T}$ (Pro198Leu) polymorphism of GPX1, the $137,346 \mathrm{~T} \rightarrow \mathrm{C}$ polymorphism of $F Y N$, the $-344 \mathrm{C} \rightarrow \mathrm{T}$ polymorphism of $C Y P 11 B 2$, and the $\mathrm{A} \rightarrow \mathrm{G}$ (Ser49Gly) polymorphism of $A D R B 1$ were determined with a fluorescence-based allelespecific DNA primer assay system; those for the $A \rightarrow G$ polymorphism of $C N R 2$, the I/D (22,375delAC) polymorphism of $C A V 1$, and the $-1213 \mathrm{~T} \rightarrow \mathrm{C}$ polymorphism of ESR 2 by melting curve analysis, and that for the $(\mathrm{GT})_{\mathrm{n}}$ polymorphism of COL1A2 were determined by DNA fragment analysis. The polymorphism of $F Y N$ was associated with systolic and diastolic BP in women. In men, polymorphisms of $C N R 2$, QPCT, GPX1, COL1A2, CYP11B2, and ESR2 were associated with systolic and diastolic BP, those of $C A V 1$ and $F Y N$ with systolic BP, and that of $A D R B 1$ with diastolic BP. The polymorphisms of $Q P C T$ and $C Y P 11 B 2$ were also
\end{abstract}

Correspondence to: Dr Yoshiji Yamada, Department of Human Functional Genomics, Life Science Research Center, Mie University, 1577 Kurima-machiya, Tsu, Mie 514-8507, Japan E-mail: yamada@gene.mie-u.ac.jp

Key words: blood pressure, hypertension, genetics, polymorphism associated with the prevalence of hypertension in men. These results suggest that polymorphisms of $Q P C T$ and $C Y P 11 B 2$ are determinants of $\mathrm{BP}$ and the development of hypertension in Japanese men.

\section{Introduction}

Hypertension is a complex multifactorial disorder that is thought to result from an interaction between an individual's genetic background and various environmental factors (1). Given that hypertension is a major risk factor for coronary heart disease, stroke, and chronic renal failure, personalized prevention of hypertension is an important public health goal. One approach to personalized prevention of, and selection of the most appropriate treatment for, hypertension is to identify genes that confer susceptibility to this condition. Although genetic linkage analyses (2-5) and candidate gene association studies (6-9) have implicated various loci and genes in the predisposition to hypertension, the genes that confer genetic susceptibility to this condition remain to be identified definitively. In addition, because of ethnic divergence of gene polymorphisms as well as of environmental factors and lifestyle, it is important to examine polymorphisms related to hypertension in each ethnic group.

We have been attempting to identify genes significantly associated with blood pressure (BP) in Japanese women or men with a population-based approach. In the present study, we selected nine candidate genes that might be expected to contribute to the regulation of BP (Table I) and examined the relations of polymorphisms of these genes to BP, even though there was no apparent biological link among these genes. Our aim was to identify a single polymorphism significantly associated with BP for each gene. Among several polymorphisms previously identified, we selected those that might be expected to affect gene function. We thus examined the relations of these polymorphisms to $\mathrm{BP}$ and the prevalence of hypertension in community-dwelling Japanese women and men.

\section{Materials and methods}

Study population. The National Institute for Longevity Sciences, the Longitudinal Study of Aging, is a population- 
Table I. The nine gene polymorphisms examined in the present study.

\begin{tabular}{|c|c|c|c|c|}
\hline Locus & Gene & Symbol & Polymorphism & dbSNP \\
\hline $1 \mathrm{p} 36.11$ & Cannabinoid receptor 2 & CNR2 & $\mathrm{A} \rightarrow \mathrm{G}$ & rs 2501431 \\
\hline $2 \mathrm{p} 22.2$ & Glutaminyl-peptide cyclotransferase & $Q P C T$ & $160 \mathrm{C} \rightarrow \mathrm{T}(\operatorname{Arg} 54 \mathrm{Trp})$ & rs2255991 \\
\hline $3 \mathrm{p} 21.3$ & Glutathione peroxidase & GPX1 & $\mathrm{C} \rightarrow \mathrm{T}($ Pro198Leu $)$ & rs 1050450 \\
\hline $6 \mathrm{q} 21$ & FYN oncogene related to SRC, FGR, YES & $F Y N$ & $137,346 \mathrm{~T} \rightarrow \mathrm{C}$ & rs706895 \\
\hline $7 \mathrm{q} 22.1$ & Collagen, type I, $\alpha-2$ & COL1A2 & $(\mathrm{GT})_{\mathrm{n}}$ & ND \\
\hline $7 \mathrm{q} 31.1$ & Caveolin 1 & $C A V 1$ & I/D (22,375delAC) & rs3840634 \\
\hline $8 \mathrm{q} 21-\mathrm{q} 22$ & Cytochrome P450, subfamily Y XIB, polypeptide 2 & $C Y P 11 B 2$ & $-344 \mathrm{C} \rightarrow \mathrm{T}$ & rs 1799998 \\
\hline $10 q 24-q 26$ & ß-1-adrenergic receptor & $A D R B 1$ & $\mathrm{~A} \rightarrow \mathrm{G}$ (Ser49Gly) & rs1801252 \\
\hline $14 q 23.2$ & Estrogen receptor 2 & ESR2 & $-1213 \mathrm{~T} \rightarrow \mathrm{C}$ & ND \\
\hline
\end{tabular}

ND, not detected in dbSNP.

based prospective cohort study of aging and age-related diseases (10). The subjects were unrelated individuals stratified by both age and sex, and were randomly selected from resident registrations in the city of $\mathrm{Obu}$ and town of Higashiura in central Japan (11-13). The lifestyle of residents of this area is typical of that of individuals in most regions of Japan. The numbers of men and women recruited were similar and the age at baseline was 40-79 years, with similar numbers of participants in each decade $(40,50,60$ and 70 s). The subjects are being followed up every 2 years. All participants were subjected at a special center to a detailed examination, which included not only medical evaluation but also assessment of exercise physiology, body composition, nutrition, and psychology. Individuals with coronary heart disease, valvular heart disease, cardiomyopathies, or renal or endocrinologic diseases that cause secondary hypertension were excluded from the present study. We thus examined the relations of gene polymorphisms to BP or the prevalence of hypertension in 2238 individuals (1110 women, 1128 men). Individuals whose genotypes were not successfully determined were excluded from the analysis. The study protocol complies with the Declaration of Helsinki and was approved by the Committee on Ethics of Human Research of the National Institute for Longevity Sciences. Written informed consent was obtained from each subject.

Measurement of BP. BP was measured with an automatic sphygmomanometer (BP-203RV-II; Colin, Tokyo, Japan) in subjects having rested in a sitting position for at least $15 \mathrm{~min}$. $\mathrm{BP}$ in each subject was confirmed with the measurement made by a physician with a mercury manometer according to the guidelines of the American Heart Association (14). Normal BP was defined as both a systolic BP of $<140 \mathrm{mmHg}$ and a diastolic BP of $<90 \mathrm{mmHg}$. Hypertension was defined as a systolic BP of $\geq 140 \mathrm{mmHg}$ or a diastolic $\mathrm{BP}$ of $\geq 90 \mathrm{mmHg}$ (or both), or the use of antihypertensive medication.

Determination of genotype. Genotypes for polymorphisms of $Q P C T, G P X 1, F Y N, C Y P 11 B 2$, and ADRB1 were determined with a fluorescence-based allele-specific DNA primer assay system (Toyobo Gene Analysis, Tsuruga, Japan) (15). Primers and other conditions for genotyping are shown in
Table II. The polymorphic region of each gene was amplified by the polymerase chain reaction (PCR) with allele-specific sense primers labeled at the $5^{\prime}$ end with either fluorescein isothiocyanate or Texas red and with an antisense primer labeled at the $5^{\prime}$ end with biotin. The reaction mixture $(25 \mu \mathrm{l})$ contained $20 \mathrm{ng}$ of DNA, $5 \mathrm{pmol}$ of each primer, $0.2 \mathrm{mmol} / \mathrm{l}$ of each deoxynucleoside triphosphate, 2.5-4 mmol/ $\mathrm{MgCl}_{2}$, and $1 \mathrm{U}$ of rTaq DNA polymerase (Toyobo, Osaka, Japan) in polymerase buffer. The amplification protocol comprised initial denaturation at $95^{\circ} \mathrm{C}$ for $5 \mathrm{~min}$; 35 cycles of denaturation at $95^{\circ} \mathrm{C}$ for $30 \mathrm{sec}$, annealing at $60-70^{\circ} \mathrm{C}$ for $30 \mathrm{sec}$, and extension at $72^{\circ} \mathrm{C}$ for $30 \mathrm{sec}$; and a final extension at $72^{\circ} \mathrm{C}$ for $2 \mathrm{~min}$. The amplified DNA was incubated with streptavidin-conjugated magnetic beads in the wells of a 96-well plate at room temperature, and the plate was then placed on a magnetic stand. The supernatants from each well were transferred to the wells of a 96-well plate containing $0.01 \mathrm{~mol} / 1$ $\mathrm{NaOH}$ and were measured for fluorescence with a microplate reader (Fluoroscan Ascent; Dainippon Pharmaceutical, Osaka, Japan) at excitation and emission wavelengths of 485 and $538 \mathrm{~nm}$, respectively, for fluorescein isothiocyanate and of 584 and $612 \mathrm{~nm}$, respectively, for Texas red.

Genotypes for polymorphisms of CNR2, CAV1, and ESR2 were determined by melting curve analysis (intercalatermediated fluorescence resonance energy transfer probe method). The polymorphic region of each gene was amplified by PCR (Table II) in a reaction mixture $(25 \mu \mathrm{l})$ containing $20 \mathrm{ng}$ of DNA, $5 \mathrm{pmol}$ of each primer, $0.2 \mathrm{mmol} / \mathrm{l}$ of each deoxynucleoside triphosphate, $2 \mathrm{mmol} / \mathrm{MgCl}_{2}$, and $1.25 \mathrm{U}$ of rTaq DNA polymerase in polymerase buffer. The amplification protocol comprised initial denaturation at $95^{\circ} \mathrm{C}$ for $5 \mathrm{~min} ; 45$ cycles of denaturation at $95^{\circ} \mathrm{C}$ for $30 \mathrm{sec}$, annealing at $65^{\circ} \mathrm{C}$ for $30 \mathrm{sec}$, and extension at $72^{\circ} \mathrm{C}$ for $30 \mathrm{sec}$; and a final extension at $72^{\circ} \mathrm{C}$ for $2 \mathrm{~min}$. A mixture $(2 \mu \mathrm{l})$ of $10 \mathrm{pmol}$ of probe and SYBR-Green was added to the PCR products, which were then transferred to a PRISM 7700 instrument (Applied Biosystems, Foster City, CA) for measurement of melting temperature. The program for analytic melting comprised incubation at $95^{\circ} \mathrm{C}$ for $30 \mathrm{sec}, 40^{\circ} \mathrm{C}$ for $1 \mathrm{~min}$, and temperatures increasing to $80^{\circ} \mathrm{C}$ over $10 \mathrm{~min}$. The fluorescence signals were detected at excitation and emission wavelengths of 485 and $612 \mathrm{~nm}$, respectively. 
Table II. Primers, probes, and other PCR conditions for genotyping.

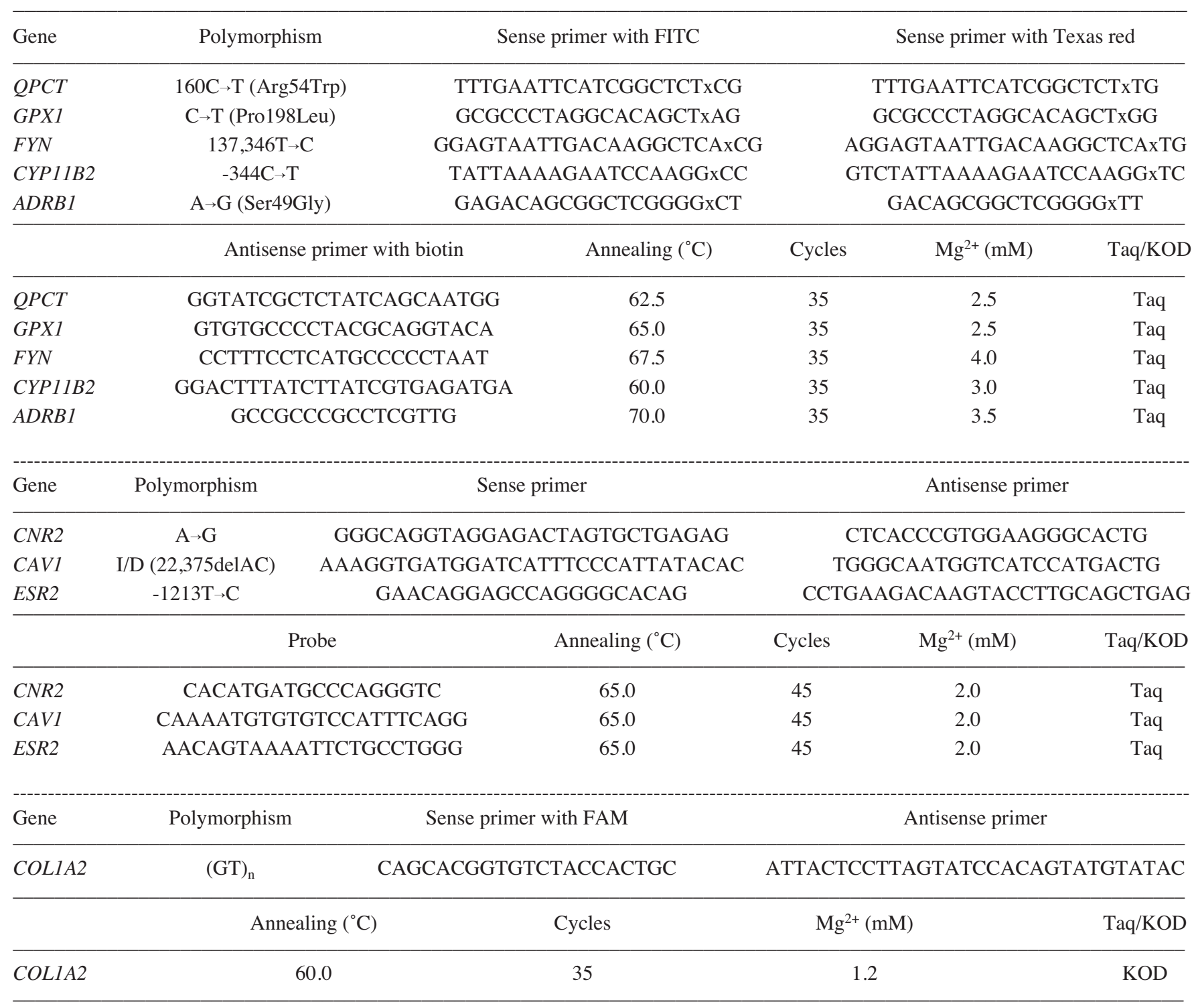

FITC, fluorescein isothiocyanate; FAM, 6-carboxyfluorescein. Oligonucleotide sequences are $5^{\prime} \rightarrow 3^{\prime}$.

The GT repeats $\left[(\mathrm{GT})_{\mathrm{n}}\right]$ in the first intron of $\mathrm{COL} 1 \mathrm{~A} 2$ were amplified by PCR with a sense primer labeled at the $5^{\prime}$ end with 6-carboxyfluorescein and with an antisense primer (Table II). The reaction mixture $(25 \mu \mathrm{l})$ contained $20 \mathrm{ng}$ of DNA, $5 \mathrm{pmol}$ of each primer, $0.2 \mathrm{mmol} / \mathrm{l}$ of each deoxynucleoside triphosphate, $1.2 \mathrm{mmol} / 1 \mathrm{MgSO}_{4}$, and $0.4 \mathrm{U}$ of KOD plus DNA polymerase (Toyobo) in polymerase buffer. The amplification protocol comprised initial denaturation at $94^{\circ} \mathrm{C}$ for $5 \mathrm{~min} ; 35$ cycles of denaturation at $94^{\circ} \mathrm{C}$ for $15 \mathrm{sec}$, annealing at $60^{\circ} \mathrm{C}$ for $30 \mathrm{sec}$, and extension at $68^{\circ} \mathrm{C}$ for $30 \mathrm{sec}$; and a final extension at $68^{\circ} \mathrm{C}$ for $2 \mathrm{~min}$. The size of the $(\mathrm{GT})_{\mathrm{n}}$-containing PCR products was determined with a PRISM 3100 DNA sequencer and with GeneScan and Genotyper software (Applied Biosystems).

Statistical analysis. Age and BP were compared among three groups by one-way analysis of variance and the TukeyKramer post hoc test, and between two groups by the unpaired Student's t-test. BP values were analyzed in individuals who were not taking antihypertensive drugs. The prevalence of hypertension was compared between two groups $(2 \times 2)$ or among three groups $(3 \times 2)$ by the Chi-square test in all individuals. Allele frequencies were estimated by the gene-counting method, and the Chi-square test was used to identify significant departure from Hardy-Weinberg equilibrium. A P value of $<0.05$ was considered statistically significant.

\section{Results}

Relation of the $A \rightarrow G$ polymorphism of $C N R 2$ to $B P$. For men, the distribution of genotypes for the $A \rightarrow G$ polymorphism of CNR2 was in Hardy-Weinberg equilibrium and individuals in the combined group of $A G$ and $G G$ genotypes were younger than those with the $A A$ genotype (Table III). Systolic and diastolic BP were significantly higher in men with the $G G$ genotype than in those with the $A A$ genotype or with the $A G$ genotype or in those in the combined group of $A A$ and $A G$ 
Table III. Blood pressure (BP) for male subjects according to CNR2 genotype.

\begin{tabular}{lccccc}
\hline Characteristics & $A A$ & $A G$ & $G G$ & $A A+A G$ & $A G+G G$ \\
\hline Number of subjects (n=874) & & 295 & 425 & 154 & 720 \\
Age (years) & $60.2 \pm 0.6$ & $58.5 \pm 0.5$ & $59.2 \pm 0.8$ & $59.2 \pm 0.4$ & $58.7 \pm 0.4^{\mathrm{b}}$ \\
Systolic BP (mmHg) & $120.5 \pm 1.0^{\mathrm{c}}$ & $120.3 \pm 0.8^{\mathrm{d}}$ & $125.0 \pm 1.4$ & $120.4 \pm 0.6^{\mathrm{e}}$ & $121.6 \pm 0.7$ \\
Diastolic BP (mmHg) & $74.8 \pm 0.6^{\mathrm{f}}$ & $74.9 \pm 0.5^{\mathrm{g}}$ & $78.0 \pm 0.9$ & $74.9 \pm 0.4^{\mathrm{h}}$ & $75.8 \pm 0.4$ \\
Number of all subjects (n=1122) & 387 & 549 & 186 & 936 & 735 \\
Hypertension (\%) & 34.4 & 33.5 & 37.6 & 33.9 & 34.6 \\
\hline
\end{tabular}

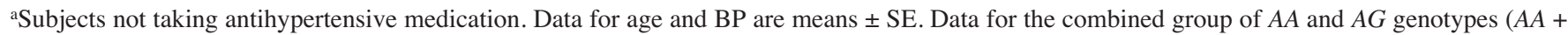
$A G$ ) were compared with those for individuals with the $G G$ genotype (recessive genetic model). Data for the combined group of $A G$ and $G G$ genotypes $(A G+G G)$ were compared with those for individuals with the $A A$ genotype (dominant genetic model). ${ }^{\mathrm{b}} \mathrm{P}=0.0313$ versus $\mathrm{AA} ;{ }^{\mathrm{c}} \mathrm{P}=0.0230$, ${ }^{\mathrm{d}} \mathrm{P}=0.0101,{ }^{\mathrm{e}} \mathrm{P}=0.0025,{ }^{\mathrm{f}} \mathrm{P}=0.0071,{ }^{\mathrm{g}} \mathrm{P}=0.0065,{ }^{\mathrm{h}} \mathrm{P}=0.0010$ versus $G G$.

Table IV. Blood pressure (BP) for male subjects according to QPCT genotype.

\begin{tabular}{lccccc}
\hline Characteristics & $C C$ & $C T$ & $T T$ & $C C+C T$ & $C T+T T$ \\
\hline Number of subjects (n=878) & 387 & 379 & 112 & 766 & 491 \\
Age (years) & $58.8 \pm 0.5$ & $59.8 \pm 0.5$ & $58.4 \pm 0.9$ & $59.3 \pm 0.4$ & $59.5 \pm 0.4$ \\
Systolic BP (mmHg) & $119.5 \pm 0.9$ & $122.4 \pm 0.9$ & $121.7 \pm 1.7$ & $121.1 \pm 0.6$ & $122.3 \pm 0.8^{\mathrm{b}}$ \\
Diastolic BP (mmHg) & $74.6 \pm 0.5$ & $76.3 \pm 0.5$ & $75.1 \pm 1.0$ & $75.5 \pm 0.4$ & $76.1 \pm 0.5^{\mathrm{c}}$ \\
Number of all subjects (n=1128) & 487 & 501 & 140 & 988 & 641 \\
Hypertension (\%) & $29.2^{\mathrm{e}}$ & $39.5^{\mathrm{e}}$ & $35.0^{\mathrm{e}}$ & 34.4 & $38.5^{\mathrm{d}}$ \\
\hline
\end{tabular}

asubjects not taking antihypertensive medication. Data for age and BP are means \pm SE. Data for the combined group of $C C$ and $C T$ genotypes $(C C+$ $C T$ ) were compared with those for individuals with the $T T$ genotype (recessive genetic model). Data for the combined group of $C T$ and $T T$ genotypes $(C T+T T)$ were compared with those for individuals with the $C C$ genotype (dominant genetic model). ${ }^{\mathrm{b}} \mathrm{P}=0.0233,{ }^{\mathrm{c}} \mathrm{P}=0.0434,{ }^{\mathrm{d}} \mathrm{P}=0.0010$ versus $\mathrm{CC}$. ${ }^{\mathrm{e}} \mathrm{P}=0.0027$ ( $C C$ versus $C T$ versus $T T, 3 \times 2$ Chi-square test).

genotypes. The differences in systolic and diastolic BP between individuals with the $G G$ genotype and those in the combined group of $A A$ and $A G$ genotypes (expressed as a percentage of the larger value) were 3.7 and $4.0 \%$, respectively. The prevalence of hypertension did not differ among CNR2 genotypes for men. For women, neither systolic or diastolic BP nor the prevalence of hypertension differed among CNR2 genotypes (data not shown).

Relation of the 160C $\rightarrow T$ (Arg54Trp) polymorphism of QPCT to $B P$. The distribution of genotypes for the $160 \mathrm{C} \rightarrow \mathrm{T}$ polymorphism of QPCT was in Hardy-Weinberg equilibrium and age did not differ among genotypes for men (Table IV). Systolic and diastolic BP were significantly greater for men in the combined group of $C T$ and $T T$ genotypes than for those with the $C C$ genotype; the differences in systolic and diastolic BP between these groups were 2.3 and $2.0 \%$, respectively. The prevalence of hypertension also differed significantly among genotypes ( $C C$ versus $C T$ versus $T T$ ), being greater for men in the combined group of $C T$ and $T T$ genotypes than for those with the $C C$ genotype. The odds ratio of the $T$ allele compared with the $C$ allele for predisposition to hypertension was 1.3. There were no differences in systolic or diastolic BP or in the prevalence of hypertension among QPCT genotypes in women (data not shown).
Relation of the $C \rightarrow T$ (Pro198Leu) polymorphism of GPX1 to $B P$. Among men, the distribution of genotypes for the $\mathrm{C} \rightarrow \mathrm{T}$ (Pro198Leu) polymorphism of GPX1 was in Hardy-Weinberg equilibrium and age did not differ among genotypes (Table V). Systolic and diastolic BP were significantly higher for men with the $C T$ genotype or for those in the combined group of $C T$ and $T T$ genotypes than for those with the $C C$ genotype. The differences in systolic and diastolic BP between individuals in the combined group of $C T$ and $T T$ genotypes and those with the $C C$ genotype were 3.6 and $3.7 \%$, respectively. The prevalence of hypertension did not differ among GPX1 genotypes for men. Among women, no difference in systolic or diastolic BP or in the prevalence of hypertension was detected among GPXI genotypes (data not shown).

Relation of the 137,346T $\rightarrow$ C polymorphism of FYN to BP. For women, the distribution of genotypes for the $137,346 \mathrm{~T} \rightarrow \mathrm{C}$ polymorphism of $F Y N$ was in Hardy-Weinberg equilibrium and age did not differ among genotypes (Table VI). Systolic and diastolic BP were significantly higher in women with the $T C$ genotype or in those in the combined group of $T C$ and $C C$ genotypes than in those with the $T T$ genotype. The differences in systolic and diastolic BP between individuals in the combined group of $T C$ and $C C$ genotypes and those 
Table V. Blood pressure (BP) for male subjects according to GPX1 genotype.

\begin{tabular}{lccccc}
\hline Characteristics & $C C$ & $C T$ & $T T$ & $C C+C T$ & $C T+T T$ \\
\hline Number of subjects $(\mathrm{n}=879)^{\mathrm{a}}$ & 750 & 126 & 3 & 876 & 129 \\
Age (years) & $59.3 \pm 0.4$ & $58.7 \pm 0.9$ & $59.0 \pm 6.3$ & $59.2 \pm 0.4$ & $58.7 \pm 0.9$ \\
Systolic BP (mmHg) & $120.5 \pm 0.6$ & $125.0 \pm 1.5^{\mathrm{b}}$ & $122.0 \pm 9.9$ & $121.2 \pm 0.6$ & $125.0 \pm 1.5^{\mathrm{c}}$ \\
Diastolic BP (mmHg) & $75.0 \pm 0.4$ & $78.0 \pm 0.9^{\mathrm{d}}$ & $71.7 \pm 6.1$ & $75.4 \pm 0.4$ & $77.9 \pm 0.9^{\mathrm{e}}$ \\
Number of all subjects (n=1128) & 971 & 154 & 3 & 1125 & 157 \\
Hypertension (\%) & 34.0 & 37.7 & 0 & 34.5 & 36.9 \\
\hline
\end{tabular}

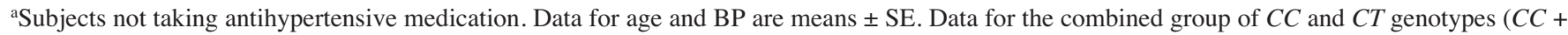
$C T$ ) were compared with those for individuals with the $T T$ genotype (recessive genetic model). Data for the combined group of $C T$ and $T T$ genotypes $(C T+T T)$ were compared with those for individuals with the $C C$ genotype (dominant genetic model). ${ }^{\mathrm{b}} \mathrm{P}=0.0188,{ }^{\mathrm{c}} \mathrm{P}=0.0072,{ }^{\mathrm{d}} \mathrm{P}=0.0078,{ }^{\mathrm{e}} \mathrm{P}=0.0040$ versus $C C$.

Table VI. Blood pressure (BP) for female subjects according to FYN genotype.

\begin{tabular}{|c|c|c|c|c|c|}
\hline Characteristics & $T T$ & $T C$ & $C C$ & $T T+T C$ & $T C+C C$ \\
\hline Number of subjects $(n=883)^{a}$ & 338 & 423 & 122 & 761 & 545 \\
\hline Age (years) & $59.0 \pm 0.5$ & $59.6 \pm 0.5$ & $58.1 \pm 0.9$ & $59.3 \pm 0.4$ & $59.3 \pm 0.3$ \\
\hline Systolic BP (mmHg) & $117.9 \pm 1.0$ & $121.6 \pm 0.9^{\mathrm{b}}$ & $119.6 \pm 1.7$ & $119.9 \pm 0.7$ & $121.1 \pm 0.8$ \\
\hline Diastolic BP (mmHg) & $71.5 \pm 0.6$ & $73.8 \pm 0.5^{\mathrm{d}}$ & $72.4 \pm 1.0$ & $72.8 \pm 0.4$ & $73.5 \pm 0.5^{\mathrm{e}}$ \\
\hline Number of all subjects $(n=1109)$ & 426 & 532 & 151 & 958 & 683 \\
\hline Hypertension (\%) & 32.4 & 37.3 & 31.8 & 35.1 & 36.1 \\
\hline
\end{tabular}

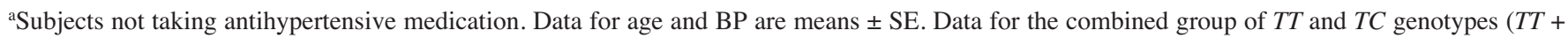
$T C$ ) were compared with those for individuals with the $C C$ genotype (recessive genetic model). Data for the combined group of $T C$ and $C C$ genotypes $(T C+C C)$ were compared with those for individuals with the $T T$ genotype (dominant genetic model). ${ }^{b} \mathrm{P}=0.0217,{ }^{\mathrm{C}} \mathrm{P}=0.0138,{ }^{\mathrm{d}} \mathrm{P}=0.0132$, ${ }^{\mathrm{e}} \mathrm{P}=0.0104$ versus $T T$.

Table VII. Blood pressure (BP) for male subjects according to FYN genotype.

\begin{tabular}{lccccc}
\hline Characteristics & $T T$ & $T C$ & $C C$ & $T T+T C$ & $T C+C C$ \\
\hline Number of subjects $(\mathrm{n}=875)^{\mathrm{a}}$ & 339 & 409 & 127 & 748 & 536 \\
Age (years) & $59.0 \pm 0.5$ & $59.4 \pm 0.5$ & $59.1 \pm 0.9$ & $59.2 \pm 0.4$ & $59.4 \pm 0.4$ \\
Systolic BP (mmHg) & $119.5 \pm 1.0$ & $122.3 \pm 0.9$ & $121.3 \pm 1.6$ & $121.2 \pm 0.6$ & $122.1 \pm 0.7^{\mathrm{b}}$ \\
Diastolic BP (mmHg) & $74.7 \pm 0.6$ & $75.8 \pm 0.5$ & $76.1 \pm 0.9$ & $75.3 \pm 0.4$ & $75.9 \pm 0.5$ \\
Number of all subjects (n=1122) & 441 & 527 & 154 & 968 & 681 \\
Hypertension (\%) & 32.4 & 36.6 & 31.8 & 34.7 & 35.5 \\
\hline
\end{tabular}

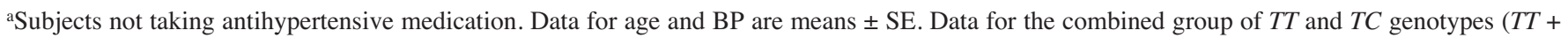
$T C$ ) were compared with those for individuals with the $C C$ genotype (recessive genetic model). Data for the combined group of $T C$ and $C C$ genotypes $\left(T C+C C\right.$ ) were compared with those for individuals with the $T T$ genotype (dominant genetic model). ${ }^{b} \mathrm{P}=0.0344$ versus $T T$.

with the $T T$ genotype were 2.6 and $2.7 \%$, respectively. The prevalence of hypertension did not differ among FYN genotypes for women.

For men, the distribution of FYN genotypes was in Hardy-Weinberg equilibrium and age did not differ among genotypes (Table VII). Systolic BP was significantly higher for men in the combined group of $T C$ and $C C$ genotypes than for those with the TT genotype; the difference in systolic BP between these groups was $2.1 \%$. The prevalence of hypertension did not differ among $F Y N$ genotypes for men.

Relation of the $(G T)_{n}$ polymorphism of COL1A2 to BP. Given that the mean and median numbers of GT repeats for COL1A2 in the study subjects were 14.2 and 12, respectively, we designated $(\mathrm{GT})_{\mathrm{n} \leq 12}$ and $(\mathrm{GT})_{\mathrm{n} \geq 13}$ as short $(S)$ and long $(L)$ alleles, respectively. The distribution of the $S S, S L$, and $L L$ 
Table VIII. Blood pressure (BP) for male subjects according to COL1A2 genotype.

\begin{tabular}{lcccrc}
\hline Characteristics & $S S$ & $S L$ & $L L$ & $S S+S L$ & $S L+L L$ \\
\hline Number of subjects (n=854) & 252 & 415 & 187 & 667 & 602 \\
Age (years) & $59.7 \pm 0.6$ & $59.4 \pm 0.5$ & $58.7 \pm 0.7$ & $59.5 \pm 0.4$ & $59.2 \pm 0.4$ \\
Systolic BP (mmHg) & $123.1 \pm 1.1$ & $120.4 \pm 0.9$ & $120.6 \pm 1.3$ & $121.4 \pm 0.7$ & $120.5 \pm 0.7^{\mathrm{b}}$ \\
Diastolic BP (mmHg) & $76.8 \pm 0.7$ & $74.7 \pm 0.5^{\mathrm{c}}$ & $75.4 \pm 0.8$ & $75.5 \pm 0.4$ & $74.9 \pm 0.4^{\mathrm{d}}$ \\
Number of all subjects (n=1095) & 308 & 543 & 244 & 851 & 787 \\
Hypertension (\%) & 33.3 & 34.6 & 36.1 & 34.2 & 35.1 \\
\hline
\end{tabular}

${ }^{a}$ Subjects not taking antihypertensive medication. Data for age and BP are means \pm SE. $S$, short repeat allele $\left[(\mathrm{GT})_{\mathrm{n}} \leq 12\right] ; L$, long repeat allele $\left[(\mathrm{GT})_{\mathrm{n}} \geq 13\right]$. Data for the combined group of $S S$ and $S L$ genotypes $(S S+S L)$ were compared with those for individuals with the $L L$ genotype (recessive genetic model). Data for the combined group of $S L$ and $L L$ genotypes $(S L+L L)$ were compared with those for individuals with the $S S$ genotype (dominant genetic model). ${ }^{\mathrm{b}} \mathrm{P}=0.0460,{ }^{\mathrm{c}} \mathrm{P}=0.0341,{ }^{\mathrm{d}} \mathrm{P}=0.0178$ versus $S S$.

Table IX. Blood pressure (BP) for male subjects according to CAVI genotype.

\begin{tabular}{|c|c|c|c|c|c|}
\hline Characteristics & $I I$ & $I D$ & $D D$ & $I I+I D$ & $I D+D D$ \\
\hline Number of subjects $(n=879)^{a}$ & 796 & 82 & 1 & 878 & 83 \\
\hline Age (years) & $59.1 \pm 0.3$ & $60.6 \pm 1.1$ & 48.0 & $59.2 \pm 0.4$ & $60.4 \pm 1.1$ \\
\hline Systolic BP (mmHg) & $120.8 \pm 0.6$ & $125.0 \pm 1.9$ & 126.0 & $121.2 \pm 0.6$ & $125.1 \pm 1.9^{\mathrm{b}}$ \\
\hline Diastolic BP $(\mathrm{mmHg})$ & $75.2 \pm 0.4$ & $77.4 \pm 1.2$ & 75.0 & $75.4 \pm 0.4$ & $77.3 \pm 1.2$ \\
\hline Number of all subjects $(n=1128)$ & 1028 & 99 & 1 & 1127 & 100 \\
\hline Hypertension $(\%)$ & 34.2 & 36.4 & 0 & 34.4 & 36.0 \\
\hline
\end{tabular}

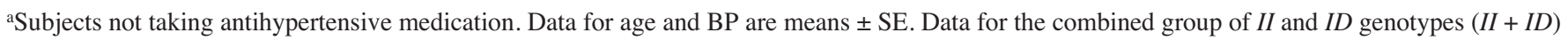
were compared with those for individuals with the $D D$ genotype (recessive genetic model). Data for the combined group of $I D$ and $D D$ genotypes $(I D+D D)$ were compared with those for individuals with the $I I$ genotype (dominant genetic model). ${ }^{\mathrm{b}} \mathrm{P}=0.0325$ versus $I I$.

genotypes of COL1A2 was in Hardy-Weinberg equilibrium and age did not differ among genotypes for men (Table VIII). Systolic BP was significantly higher in men with the $S S$ genotype than in those in the combined group of $S L$ and $L L$ genotypes, whereas diastolic BP was significantly higher in men with the $S S$ genotype than in those with the $S L$ genotype or in those in the combined group of $S L$ and $L L$ genotypes. The differences in systolic and diastolic BP between individuals with the $S S$ genotype and those in the combined group of $S L$ and $L L$ genotypes were 2.1 and $2.5 \%$, respectively. The prevalence of hypertension did not differ among COL1A2 genotypes for men. There were no differences in systolic or diastolic BP or in the prevalence of hypertension among COL1A2 genotypes in women (data not shown).

Relation of the I/D (22,375delAC) polymorphism of CAV1 to $B P$. For men, the distribution of genotypes for the 22,375 I/D polymorphism of $C A V 1$ was in Hardy-Weinberg equilibrium and age did not differ among genotypes (Table IX). Systolic BP was significantly higher for men in the combined group of $I D$ and $D D$ genotypes than for those with the II genotype; the difference in systolic BP between these groups was $3.4 \%$. The prevalence of hypertension did not differ among CAVI genotypes for men. For women, neither systolic or diastolic $\mathrm{BP}$ nor the prevalence of hypertension differed among CAVI genotypes (data not shown).
Relation of the $-344 C \rightarrow T$ polymorphism of $C Y P 11 B 2$ to BP. The distribution of genotypes for the $-344 \mathrm{C} \rightarrow \mathrm{T}$ polymorphism of $C Y P 11 B 2$ was in Hardy-Weinberg equilibrium and age did not differ among genotypes for men (Table X). Systolic and diastolic BP were significantly higher in men with the $C T$ genotype or with the TT genotype or in those in the combined group of $C T$ and $T T$ genotypes than in those with the CC genotype. The difference in systolic or diastolic BP between individuals in the combined group of $C T$ and $T T$ genotypes and those with the $C C$ genotype was $4.9 \%$. The prevalence of hypertension also differed significantly among genotypes ( $C C$ versus $C T$ versus $T T$ ), being greater for men in the combined group of $C T$ and $T T$ genotypes than for those with the $C C$ genotype. The odds ratio of the $T$ allele compared with the $C$ allele for predisposition to hypertension was 1.2. Although there were no differences in systolic or diastolic BP among CYP11B2 genotypes in women (data not shown), the prevalence of hypertension differed among genotypes [CC (26.6\%) versus $C T(33.9 \%)$ versus $T T(38.3 \%), \mathrm{P}=0.0333]$, being greater for women in the combined group of $C T$ and TT genotypes $(36.0 \%)$ than for those with the $C C$ genotype (26.6\%, $\mathrm{P}=0.0272$ ) as well as greater for women with the $T T$ genotype $(38.3 \%)$ than for those in the combined group of $C C$ and $C T$ genotypes $(32.3 \%, \mathrm{P}=0.0387)$. The odds ratio of the $T$ allele compared with the $C$ allele for predisposition to hypertension was 1.3 . 
Table X. Blood pressure (BP) for male subjects according to CYP11B2 genotype.

\begin{tabular}{|c|c|c|c|c|c|}
\hline Characteristics & $C C$ & $C T$ & $T T$ & $C C+C T$ & $C T+T T$ \\
\hline Number of subjects $(n=876)^{a}$ & 109 & 418 & 349 & 527 & 767 \\
\hline Age (years) & $59.5 \pm 1.0$ & $59.1 \pm 0.5$ & $59.2 \pm 0.5$ & $59.2 \pm 0.4$ & $59.1 \pm 0.4$ \\
\hline Systolic BP (mmHg) & $115.9 \pm 1.7$ & $122.6 \pm 0.8^{\mathrm{b}}$ & $121.1 \pm 0.9^{c}$ & $121.2 \pm 0.8$ & $121.9 \pm 0.6^{\mathrm{d}}$ \\
\hline Diastolic BP (mmHg) & $72.2 \pm 1.0$ & $76.2 \pm 0.5^{\mathrm{e}}$ & $75.5 \pm 0.6^{\mathrm{f}}$ & $75.3 \pm 0.5$ & $75.9 \pm 0.4^{\mathrm{g}}$ \\
\hline Number of all subjects $(n=1125)$ & 130 & 541 & 454 & 671 & 995 \\
\hline Hypertension (\%) & $23.9^{\mathrm{i}}$ & $35.3^{\mathrm{i}}$ & $36.6^{\mathrm{i}}$ & 33.1 & $35.9^{\mathrm{h}}$ \\
\hline
\end{tabular}

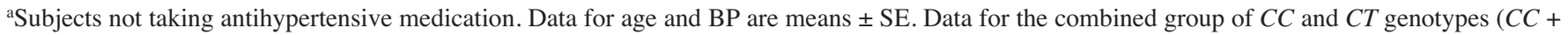
$C T$ ) were compared with those for individuals with the $T T$ genotype (recessive genetic model). Data for the combined group of $C T$ and $T T$ genotypes $(C T+T T)$ were compared with those for individuals with the $C C$ genotype (dominant genetic model). ${ }^{\mathrm{b}} \mathrm{P}=0.0010,{ }^{\mathrm{c}} \mathrm{P}=0.0171,{ }^{\mathrm{d}} \mathrm{P}=0.0007,{ }^{\mathrm{e}} \mathrm{P}=0.0014$, ${ }^{\mathrm{f}} \mathrm{P}=0.0115,{ }^{\mathrm{g}} \mathrm{P}=0.0007,{ }^{\mathrm{h}} \mathrm{P}=0.0053$ versus $C C$. ${ }^{\mathrm{i}} \mathrm{P}=0.0188$ ( $C C$ versus $C T$ versus $T T, 3 \times 2$ Chi-square test).

Table XI. Blood pressure (BP) for male subjects according to ADRB1 genotype.

\begin{tabular}{lccccc}
\hline Characteristics & $A A$ & $A G$ & $G G$ & $A A+A G$ & $A G+G G$ \\
\hline Number of subjects (n=876) & 627 & 233 & 16 & 860 & 249 \\
Age (years) & $59.1 \pm 0.4$ & $59.7 \pm 0.6$ & $59.2 \pm 2.4$ & $59.3 \pm 0.4$ & $59.7 \pm 0.6$ \\
Systolic BP (mmHg) & $120.6 \pm 0.7$ & $122.6 \pm 1.1$ & $125.9 \pm 4.3$ & $121.1 \pm 0.6$ & $122.8 \pm 1.1$ \\
Diastolic BP (mmHg) & $75.0 \pm 0.4$ & $76.4 \pm 0.7$ & $79.5 \pm 2.7$ & $75.4 \pm 0.4$ & $76.6 \pm 0.7^{\mathrm{b}}$ \\
Number of all subjects (n=1125) & 804 & 301 & 20 & 1105 & 321 \\
Hypertension (\%) & 33.7 & 35.9 & 45.0 & 34.3 & 36.5 \\
\hline
\end{tabular}

${ }^{a}$ Subjects not taking antihypertensive medication. Data for age and BP are means \pm SE. Data for the combined group of $A A$ and $A G$ genotypes $(A A+$ $A G$ ) were compared with those for individuals with the $G G$ genotype (recessive genetic model). Data for the combined group of $A G$ and $G G$ genotypes $(A G+G G)$ were compared with those for individuals with the $A A$ genotype (dominant genetic model). ${ }^{b} \mathrm{P}=0.0430$ versus $A A$.

Relation of the $A \rightarrow G$ (Ser49Gly) polymorphism of ADRB1 to $B P$. For men, the distribution of genotypes for the $A \rightarrow G$ polymorphism of $A D R B 1$ was in Hardy-Weinberg equilibrium and age did not differ among genotypes (Table XI). Diastolic $\mathrm{BP}$ was significantly higher for men in the combined group of $A G$ and $G G$ genotypes than for those with the $A A$ genotype, the difference in diastolic BP between these groups being $2.1 \%$. The prevalence of hypertension did not differ among $A D R B 1$ genotypes for men. Although systolic and diastolic $\mathrm{BP}$ did not differ among $A D R B 1$ genotypes for women (data not shown), the prevalence of hypertension differed significantly among genotypes $[A A(32.6 \%)$ versus $A G$ $(41.4 \%)$ versus $G G(29.6 \%), \mathrm{P}=0.0270]$, being greater for women in the combined group of $A G$ and $G G$ genotypes (40.3\%) than for those with the $A A$ genotype $(32.6 \%$, $\mathrm{P}=0.0156)$. The odds ratio of the $G$ allele compared with the $\mathrm{T}$ allele for predisposition to hypertension was 1.3 .

Relation of the $-1213 T \rightarrow C$ polymorphism of ESR2 to BP. In men, the distribution of genotypes for the $-1213 \mathrm{~T} \rightarrow \mathrm{C}$ polymorphism of ESR2 was not in Hardy-Weinberg equilibrium and age did not differ among genotypes (Table XII). Systolic and diastolic BP were significantly higher in men with the $T C$ genotype or in those in the combined group of $T C$ and $C C$ genotypes than in those with the $T T$ genotype. The differences in systolic and diastolic BP between individuals in the combined group of $T C$ and $C C$ genotypes and those with the $T T$ genotype were 3.3 and $4.2 \%$, respectively. The prevalence of hypertension did not differ among ESR2 genotypes for men. For women, there was no difference in systolic or diastolic BP or in the prevalence of hypertension among ESR2 genotypes (data not shown).

\section{Discussion}

The regulation of blood pressure involves the integration of a variety of biological systems that control the structure and tone of the vasculature as well as the volume and composition of body fluid. It also involves the adaptation of these systems to constantly changing physiological needs (16). We have now examined the relations of nine candidate gene polymorphisms to BP and the prevalence of hypertension in community-dwelling Japanese women and men. Our results show that the polymorphism of $F Y N$ was associated with systolic and diastolic BP in women as well as with systolic $\mathrm{BP}$ in men; the polymorphisms of $C N R 2, Q P C T, G P X 1$, COL1A2, CYP11B2, and ESR2 with systolic and diastolic BP in men; and those of $C A V I$ and $A D R B 1$ with systolic and diastolic BP, respectively, in men. The polymorphisms of $Q P C T$ and $C Y P 11 B 2$ were also associated with the prevalence 
Table XII. Blood pressure (BP) for male subjects according to ESR2 genotype.

\begin{tabular}{|c|c|c|c|c|c|}
\hline Characteristics & $T T$ & $T C$ & $C C$ & $T T+T C$ & $T C+C C$ \\
\hline Number of subjects $(n=879)^{a}$ & 773 & 97 & 9 & 870 & 106 \\
\hline Age (years) & $59.4 \pm 0.3$ & $57.4 \pm 1.0$ & $61.7 \pm 3.3$ & $59.2 \pm 0.4$ & $57.7 \pm 0.9$ \\
\hline Systolic BP (mmHg) & $120.7 \pm 0.6$ & $125.5 \pm 1.7^{\mathrm{b}}$ & $117.2 \pm 5.7$ & $121.2 \pm 0.6$ & $124.8 \pm 1.7^{\mathrm{c}}$ \\
\hline Diastolic BP (mmHg) & $75.0 \pm 0.4$ & $79.0 \pm 1.1^{\mathrm{d}}$ & $70.9 \pm 3.5$ & $75.5 \pm 0.4$ & $78.3 \pm 1.0^{\mathrm{e}}$ \\
\hline Number of all subjects $(n=1128)$ & 991 & 126 & 11 & 1117 & 137 \\
\hline Hypertension (\%) & 33.5 & 42.1 & 27.3 & 34.5 & 40.9 \\
\hline
\end{tabular}

a Subjects not taking antihypertensive medication. Data for age and BP are means \pm SE. Data for the combined group of $T T$ and $T C$ genotypes $(T T+$ $T C$ ) were compared with those for individuals with the $C C$ genotype (recessive genetic model). Data for the combined group of $T C$ and $C C$ genotypes $(T C+C C)$ were compared with those for individuals with the $T T$ genotype (dominant genetic model). ${ }^{b} \mathrm{P}=0.0257,{ }^{\mathrm{c}} \mathrm{P}=0.0212,{ }^{\mathrm{d}} \mathrm{P}=0.0014$, ${ }^{\mathrm{e}} \mathrm{P}=0.0027$ versus $T T$.

of hypertension in men. These observations thus suggest that polymorphisms of $Q P C T$ and $C Y P 11 B 2$ are determinants of $\mathrm{BP}$ and the development of hypertension in Japanese men.

Given that selection bias can influence the results of genetic association studies, it is important that study populations be genetically and ethnically homogeneous. Our study subjects were recruited randomly from individuals residing in the city of Obu and town of Higashiura in central Japan, where the population is thought to share the same ethnic ancestry and to possess a homogeneous genetic background. We also showed that, with the exception of ESR2, the genotype distributions of the examined polymorphisms were in Hardy-Weinberg equilibrium in the study population. We thus appeared to avoid admixture and selection bias.

We detected associations of all nine polymorphisms with BP in men, whereas only the $F Y N$ polymorphism was associated with BP in women. The reason for this sex difference remains unclear. It might, however, be attributable, at least in part, to the difference in the plasma concentration of estrogen between men and women, given that estrogen exerts various favorable effects on vasomotor function, including stimulation of the production of nitric oxide and prostaglandin $I_{2}$ as well as inhibition of the release of endothelin-1 by vascular endothelial cells (17).

The formation of amino-terminal pyroglutamate from its glutaminyl precursor is an important posttranslational or cotranslational event in the processing of numerous bioactive neuropeptides, hormones, and cytokines during their maturation in the secretory pathway. These regulatory peptides require the amino-terminal pyroglutamate to develop the correct conformation for binding to their receptors or to protect their amino termini from exopeptidase-mediated degradation $(18,19)$. The glutaminyl cyclases are acyltransferases that catalyze this posttranslational modification $(20,21)$. They are abundant in mammalian neuroendocrine tissues, such as the hypothalamus and pituitary gland $(21,22)$, and are highly conserved from yeast to humans. In humans, the glutaminyl-peptide cyclotransferase (glutaminyl cyclase) gene $(Q P C T)$ is located at chromosomal position 2p22.2. Ezura et al (23) examined the relations of 13 polymorphisms in this region to bone mineral density (BMD) in adult women and detected associations between the genotypes of six polymorphisms and BMD for the radius. The $160 \mathrm{C} \rightarrow \mathrm{T}$
(Arg54Trp) polymorphism of QPCT showed the most pronounced association, with the $T$ allele being associated with low BMD. These results indicate that genetic variation in $Q P C T$ is an important determinant of BMD in adult women and may therefore contribute to susceptibility to osteoporosis. We have now shown that the $160 \mathrm{C} \rightarrow \mathrm{T}$ (Arg54Trp) polymorphism of QPCT was associated both with systolic and diastolic BP and with the prevalence of hypertension in Japanese men, with the $T$ allele being associated with high BP. The effect of this polymorphism on gene expression or protein function has not been determined. This is the first demonstration of an association of this polymorphism of $Q P C T$ with BP or the prevalence of hypertension, but the underlying molecular mechanism of the association remains to be elucidated.

The cytochrome P450, subfamily Y XIB, polypeptide 2 (aldosterone synthase) gene (CYP11B2) encodes an enzyme that participates in the terminal steps of aldosterone synthesis in the zona glomerulosa cells of human adrenal glands, and its expression is regulated by angiotensin II and potassium (24). The candidacy of this gene in the present study is based on its pathogenic role in the syndrome of glucocorticoid-remediable aldosteronism (25). Several common polymorphisms of CYP11B2 have been described (26-28). The $-344 \mathrm{C} \rightarrow \mathrm{T}$ polymorphism, which is located in a putative binding site for a steroidogenic transcription factor, has been associated with hypertension (29-31) and with other hypertensive intermediate phenotypes such as plasma aldosterone level (32), urinary aldosterone excretion rate (30), and the aldosterone/renin ratio $(27,28)$. Although some studies have not confirmed these relations $(33,34)$, this locus may be important in the regulation of $\mathrm{BP}$ and the development of hypertension (35). We have now shown that the $-344 \mathrm{C} \rightarrow \mathrm{T}$ polymorphism of CYP11B2 was associated with both systolic and diastolic BP and the prevalence of hypertension in Japanese men, with the $T$ allele being associated with high BP. Our results are thus consistent with previous observations (29-31).

Given the multiple comparisons of genotypes with BP or the prevalence of hypertension in the present study, it is not possible to completely exclude potential statistical errors such as false positives. It is also possible that one or more of the polymorphisms associated with BP or the prevalence of hypertension in our study are in linkage disequilibrium with 
other polymorphisms of the same genes or of nearby genes that are actually responsible for the development of high BP. Furthermore, the relevance of the identified polymorphisms to gene transcription or to protein structure or function was not determined in the present study.

In conclusion, our results implicate $Q P C T$ and $C Y P 11 B 2$ in the regulation of $\mathrm{BP}$ and the development of hypertension in Japanese men. Determination of genotypes for these polymorphisms may prove informative for assessment of the genetic risk for hypertension and may contribute to the personalized prevention of this condition. Given that multiple variants, each having a small effect, will likely ultimately be found to be responsible for a large fraction of the genetic component of essential hypertension, identification of additional hypertension susceptibility genes will allow more accurate assessment of the genetic component of this condition.

\section{Acknowledgements}

This work was supported in part by Research Grants for Longevity Sciences (18C-02) from the Ministry of Health, Labor, and Welfare of Japan (to Y.Y., F.A., and H.S.).

\section{References}

1. Lifton RP, Gharavi AG and Geller DS: Molecular mechanisms of human hypertension. Cell 104: 545-556, 2001.

2. Caulfield M, Munroe P, Pembroke J, et al: Genome-wide mapping of human loci for essential hypertension. Lancet 361: 2118-2123, 2003

3. Gong M, Zhang H, Schulz H, et al: Genome-wide linkage reveals a locus for human essential (primary) hypertension on chromosome 12p. Hum Mol Genet 12: 1273-1277, 2003.

4. de Lange M, Spector TD and Andrew T: Genome-wide scan for blood pressure suggests linkage to chromosome 11, and replication of loci on 16, 17, and 22. Hypertension 44: 872-877, 2004.

5. Wallace C, Xue MZ, Newhouse SJ, et al: Linkage analysis using co-phenotypes in the BRIGHT study reveals novel potential susceptibility loci for hypertension. Am J Hum Genet 79: 323-331, 2006.

6. Cusi D, Barlassina C, Azzani T, et al: Polymorphisms of $\alpha-$ adducin and salt sensitivity in patients with essential hypertension. Lancet 349: 1353-1357, 1997.

7. Siffert W, Rosskopf D, Siffert G, et al: Association of a human G-protein 33 subunit variant with hypertension. Nat Genet 18: 45-48, 1998.

8. Izawa H, Yamada Y, Okada T, Tanaka M, Hirayama H and Yokota M: Prediction of genetic risk for hypertension. Hypertension 41: 1035-1040, 2003.

9. Yamada Y, Matsuo H, Segawa T, et al: Assessment of the genetic component of hypertension. Am J Hypertens 19: 1158-1165, 2006.

10. Shimokata H, Ando F and Niino N: A new comprehensive study on aging - the National Institute for Longevity Sciences, Longitudinal Study of Aging (NILS-LSA). J Epidemiol 10: S1-S9, 2000.

11. Yamada Y, Ando F, Niino N and Shimokata H: Association of polymorphisms of interleukin-6, osteocalcin, and vitamin D receptor genes, alone or in combination, with bone mineral density in community-dwelling Japanese women and men. J Clin Endocrinol Metab 88: 3372-3378, 2003.

12. Yamada Y, Ando F, Niino N and Shimokata H: Association of polymorphisms of androgen receptor and klotho genes with bone mineral density in Japanese women. J Mol Med 83: 50-57, 2005.

13. Yamada Y, Ando F and Shimokata H: Association of a microsomal triglyceride transfer protein gene polymorphism with blood pressure in Japanese women. Int J Mol Med 17: 83-88, 2006.

14. Perloff D, Grim C, Flack J, et al: Human blood pressure determination by sphygmomanometry. Circulation 88: 2460-2470, 1993.
15. Yamada Y, Izawa H, Ichihara S, et al: Prediction of the risk of myocardial infarction from polymorphisms in candidate genes. N Engl J Med 347: 1916-1923, 2002.

16. Lalouel J-M and Rohrwasser A: Development of genetic hypotheses in essential hypertension. J Hum Genet 46: 299-306, 2001.

17. Koh KK: Effects of estrogen on the vascular wall: vasomotor function and inflammation. Cardiovasc Res 55: 714-726, 2002.

18. Van Coillie E, Proost P, Van Aelst I, et al: Functional comparison of two human monocyte chemotactic protein-2 isoforms, role of the amino-terminal pyroglutamic acid and processing by CD26/dipeptidyl peptidase IV. Biochemistry 37: 12672-12680, 1998

19. Hinke SA, Pospisilik JA, Demuth HU, et al: Dipeptidyl peptidase IV (DPIV/CD26) degradation of glucagon. Characterization of glucagon degradation products and DPIV-resistant analogs. J Biol Chem 275: 3827-3834, 2000.

20. Fischer WH and Spiess J: Identification of a mammalian glutaminyl cyclase converting glutaminyl into pyroglutamyl peptides. Proc Natl Acad Sci USA 84: 3628-3632, 1987.

21. Busby WHJ, Quackenbush GE, Humm J, Youngblood WW and Kizer JS: An enzyme(s) that converts glutaminyl-peptides into pyroglutamyl-peptides. Presence in pituitary, brain, adrenal medulla, and lymphocytes. J Biol Chem 262: 8532-8536, 1987.

22. Sykes PA, Watson SJ, Temple JS and Bateman RC Jr: Evidence for tissue-specific forms of glutaminyl cyclase. FEBS Lett 455 : 159-161, 1999.

23. Ezura Y, Kajita M, Ishida R, et al: Association of multiple nucleotide variations in the pituitary glutaminyl cyclase gene (QPCT) with low radial BMD in adult women. J Bone Miner Res 19: 1296-1301, 2004

24. Clyne CD, Zhang Y, Slutsker L, Mathis JM, White PC and Rainey WE: Angiotensin II and potassium regulate human CYP11B2 transcription through common cis-elements. Mol Endocrinol 11: 638-649, 1997.

25. Lifton RP, Dluhy RG, Powers M, et al: A chimaeric 11Bhydroxylase/aldosterone synthase gene causes glucocorticoidremediable aldosteronism and human hypertension. Nature 355 : 262-265, 1992.

26. Kumar NN, Benjafield AV, Lin RC, Wang WY, Stowasser M and Morris BJ: Haplotype analysis of aldosterone synthase gene CYP11B2 polymorphisms shows association with essential hypertension. J Hypertens 21: 1331-1337, 2003.

27. Lim PO, MacDonald TM, Holloway C, et al: Variation at the aldosterone synthase $(C Y P 11 B 2)$ locus contributes to hypertension in subjects with a raised aldosterone-to-renin ratio. J Clin Endocrinol Metab 87: 4398-4402, 2002.

28. Nicod J, Bruhin D, Auer L, Vogt B, Frey FJ and Ferrari P: A biallelic gene polymorphism of $C Y P 11 B 2$ predicts increased aldosterone to renin ratio in selected hypertensive patients. J Clin Endocrinol Metab 88: 2495-2500, 2003.

29. Brand E, Chatelain N, Mulatero P, et al: Structural analysis and evaluation of the aldosterone synthase gene in hypertension. Hypertension 32: 198-204, 1998.

30. Davies E, Holloway CD, Ingram MC, et al: Aldosterone excretion rate and blood pressure in essential hypertension are related to polymorphic differences in the aldosterone synthase gene CYP11B2. Hypertension 33: 703-707, 1999.

31. Barbato A, Russo P, Siani A, et al: Aldosterone synthase gene (CYP11B2) C-344T polymorphism, plasma aldosterone, renin activity and blood pressure in a multi-ethnic population. $\mathrm{J}$ Hypertens 22: 1895-1901, 2004.

32. Russo P, Siani A, Venezia A, et al: Interaction between the $\mathrm{C}(-344) \mathrm{T}$ polymorphism of CYP11B2 and age in the regulation of blood pressure and plasma aldosterone levels: cross-sectional and longitudinal findings of the Olivetti Prospective Heart Study. J Hypertens 20: 1785-1792, 2002.

33. Brand E, Schorr U, Ringel J, Beige J, Distler A and Sharma AM: Aldosterone synthase gene (CYP11B2) C-344T polymorphism in Caucasians from the Berlin Salt-Sensitivity Trial (BeSST). J Hypertens 17: 1563-1567, 1999.

34. Schunkert H, Hengstenberg C, Holmer SR, et al: Lack of association between a polymorphism of the aldosterone synthase gene and left ventricular structure. Circulation 99: 2255-2260, 1999

35. Davies E and Kenyon CJ: CYP11B2 polymorphisms and cardiovascular risk factors. J Hypertens 21: 1249-1253, 2003. 